\title{
Mengajarkan Pendidikan Karakter Melalui Matius 5:6-12
}

${ }^{1}$ Noh Ibrahim Boiliu, ${ }^{2}$ Aeron Frior Sihombing, ${ }^{3}$ Christina M. Samosir, ${ }^{4}$ Fredy Simanjuntak

1,3Prodi Pendidikan Agama Kristen, Fakultas Keguruan dan Ilmu Pendidikan,

Universitas Kristen Indonesia, Jakarta, Indonesia

${ }^{2}$ Sekolah Tinggi Teologi Studi Alkitab untuk Pengembangan Pedesaan Indonesia, Jawa Barat,

Indonesia

${ }^{4}$ Sekolah Tinggi Teologi REAL Batam, Kepulauan Riau, Indonesia

${ }^{1}$ boiliunoh@gmail.com, 2aeronsihombing@gmail.com,

3metha.samosir@yahoo.co.id,4fredygrace@gmail.com

\begin{tabular}{|c|c|}
\hline $\begin{array}{l}\text { Article History } \\
\text { Submitted: } \\
06 \text { January } 2020\end{array}$ & $\begin{array}{l}\text { Abstract: The background of the problem in this study is the occurrence of } \\
\text { changes in the current generation due to mass media that change the mindsets, } \\
\text { behavior, and habits of today's youth, accompanied by education that tends to }\end{array}$ \\
\hline $\begin{array}{l}\text { Revised: } \\
31 \text { March } 2020\end{array}$ & $\begin{array}{l}\text { be based on knowledge or cognitive. All of this will result in humans not being } \\
\text { human. Thus, character education offered by Jesus in a happy speech at the }\end{array}$ \\
\hline $\begin{array}{l}\text { Accepted: } \\
14 \text { April } 2020\end{array}$ & $\begin{array}{l}\text { Sermon on the Mount is character-based education centered on the imitation of } \\
\text { Christ, which is to follow in the footsteps or steps of Christ in the lives of }\end{array}$ \\
\hline $\begin{array}{l}\text { Keywords: } \\
\text { character } \\
\text { education; }\end{array}$ & $\begin{array}{l}\text { Christian Character education is. Thus, this research will use an asynchronous } \\
\text { method that is to exegete what is said in the text of Matthew 5:6-12. }\end{array}$ \\
\hline & $\begin{array}{l}\text { Abstrak: Latar belakang dari masalah dalam penelitian ini adalah terjadinya } \\
\text { perubahan pada generasi saat ini karena media massa yang mengubah pola }\end{array}$ \\
\hline $\begin{array}{l}\text { khotbah di bukit; } \\
\text { pendidikan } \\
\text { karakter. }\end{array}$ & $\begin{array}{l}\text { pikir, perilaku, dan kebiasaan pemuda saat ini, disertai dengan pendidikan yang } \\
\text { cenderung didasarkan pada pengetahuan atau kognitif. Semua ini akan meng- }\end{array}$ \\
\hline Matius 5 & $\begin{array}{l}\text { akibatkan manusia tidak manusia. Dengan demikian, pendidikan Karakter yang } \\
\text { diajarkan Yesus melalui khotbah ucapan bahagia di bukit merupakan pengajaran }\end{array}$ \\
\hline & $\begin{array}{l}\text { berbasis karakter yang berpusat pada meniru Kristus, yang mengikuti jejak atau } \\
\text { langkah Kristus dalam kehidupan siswa Kristen Indonesia. Kerangka pemikiran } \\
\text { atau pandangan dunia ini adalah apa yang pendidikan karakter Kristen. Dengan }\end{array}$ \\
\hline $\begin{array}{l}\text { DOl: https://doi.org/ } \\
\text { 10.30995/kur.v6i1.128 }\end{array}$ & $\begin{array}{l}\text { demikian, penelitian ini akan menggunakan metode asynchronous yaitu untuk } \\
\text { penafsir apa yang dikatakan dalam teks Matius 5:6-12. }\end{array}$ \\
\hline
\end{tabular}

\section{Pendahuluan}

Groome dalam Noh Ibrahim Boiliu bertanya apakah yang sebenarnya dilakukan dalam tindakan mendidik? Pertanyaan Groome tersebut dibalikkan oleh Boiliu yaitu mengapa manusia harus dididik? Apakah tujuan manusia dididik? Apakah hanya sebatas pengetahuan; pengembangan akal atau otak manusia, keahlian maupun gelar? ${ }^{1}$ Ironisnya, bahwa "generasi zaman sekarang adalah generasi pemberontak akibat pengaruh media massa, narkoba, konsep intelektualitas mengantikan moralitas." "Ini adalah latar belakang dari penelitian ini, bahwa

\footnotetext{
${ }^{1}$ Noh Ibrahim Boiliu, "Misi Pendidikan Agama Kristen Dan Problem Moralitas Anak”, dalam Jurnal Pendidikan Agama Kristen Regula Fidei, Volume 1, Nomor 1, Maret 2016, 119.

${ }^{2}$ Ibid.
} 
pendidikan karakter sangat penting untuk mengubah siswa dari generasi pemberontak pada pengikut Kristus. Hal ini juga disampaikan oleh Lickona dalam Wilhelm bahwa "teori dan praktek pendidikan karakter di sekolah umum mengalami kebangkitan pada 1990-an dan telah menerima perhatian yang signifikan dalam dekade terakhir sebagai spesialisasi dalam pendidikan yang mana mencari sarana untuk mengatasi."3 Sama seperti Lickona, Boiliu dan Samosir ${ }^{4}$, sebagaimana Ferguson yang berpendapat sama bahwa "apakah beralih ke program pendidikan karakter dengan harapan untuk membantu anak dengan nilai kesopanan dan integritas, terhadap pemusnahan budaya populer yang sering tampak." Dalam penelitiannya Mark A. Pike menunjukkan bahwa "menyediakan pendidikan berkualitas tinggi untuk semua siswa mereka, terlepas dari iman. ${ }^{6}$ Pike berpendapat bahwa di tiga sekolah tempatnya meneliti bahwa nilai inti dari sekolah yang dijelaskan di sini tidak diilhami oleh agama pada umumnya, melainkan oleh tradisi Yahudi-Kristen pada khususnya.

Berdasarkan pada masalah di atas, makalah ini bertujuan untuk menuliskan bagaimana memahami pendidikan karakter melalui khotbah Tuhan Yesus di bukit yang terdapat dalam Matius 5:6-12. Penelitian ini dibatasi pada ayat 6-12, karena bagian ini merupakan mognum opus dari kotbah di bukit dan juga jantung dari pendidikan karakter. Hal ini terwujud dalam pencarian kebenaran yang berasal dari hati yang diubahkan. Asumsinya adalah bahwa apa yang Yesus katakan atau diajarkan adalah sama dengan apa yang dia lakukan atau tidak. Ajaran atau perkataan Yesus dipraktikkan dalam perkataan atau tindakannya. Demikian juga, tindakan atau tindakan Yesus adalah terjemahan dari perkataan dan ajaran-Nya."7 Dengan kata lain, "tindakan Yesus adalah untuk menjadi tercerahkan."

\section{Metode Penelitian}

Metode yang digunakan untuk penelitian ini adalah metode sinkronik, yaitu metode yang berangkat dari pandangan bahwa Alkitab merupakan suatu karya tulis yang utuh. ${ }^{9}$ Metode ini menaruh perhatian pada struktur berdasarkan isi atau pemahaman yang terdapat dalam teks Alkitab, sehingga penelitian ini akan melihat makna apa yang terdapat di balik Matius 5:6-12 secara hermeneutis. Selain itu, metode analisis teks digunakan untuk memperoleh pemahaman teks secara mendalam, dengan membandingkan beberapa pandangan para ahli Perjanjian Baru demi memperoleh konsep yang lebih baik untuk diterapkan dalam proses pendidikan karakter siswa di sekolah maupun di gereja.

\footnotetext{
${ }^{3}$ Gretchen M. Wilhelm and Michael W. Firmin, "Character Education: Christian Education Perspectives," Journal of Research on Christian Education 17, no. 2 (2008): 182-98, https://doi.org/10.1080/10656210802433384.

${ }^{4}$ Noh Ibrahim Boiliu and Christina Metallica Samosir, "Manusia Sebagai Makhluk Moral dalam Perspektif Teologia Pendidikan Johann Heinrich Pestalozzi," Jurnal Dinamika Pendidikan 12, no. 3 (2019): $187-97$.

${ }^{5}$ Wilhelm and Firmin, "Character Education: Christian Education Perspectives."

${ }^{6}$ Mark A. Pike, "The Value of Christian-Ethos Schooling for Secular Students," Journal of Research on Christian Education 20, no. 2 (2011): 138-54, https://doi.org/10.1080/10656219.2011.590728.

${ }^{7}$ Hans Kung, On Being A Christian (New York: Doubel \& Company, 1974), 463-466.

${ }^{8}$ Aeron Frior Sihombing, "Pendidikan Kristen Yang Mencerahkan"," Jurnal Te Deum: Jurnal Teologi Dan Pengembangan Pelayanan 5, no. 2 (2016): 151.

${ }^{9}$ Haposan Silalahi, "Sebuah Metode Hermeneutik dalam Menemukan Makna yang Tersembunyi dalam TeksTeks Alkitab", Te Deum-Jurnal Teologi dan Pengembangan Pelayanan Volume 8, Nomor 1, STT SAPPI: JuliDesember 2018, 17-49.
} 


\section{Pembahasan}

Joachim Jeremias lebih tegas mengatakan "Jesus did not confine himself to spoken parables, but also performed parabolic action." 10 Pengajaran Yesus dengan menggunakan parabola maupun metafora merupakan simbol dari tindakan-Nya. Tindakan simbolisnya melalui perumpamaan merupakan proklamasi akan hadirnya Kerajaan Allah di bumi. Yesus tidak hanya proklamasi ajaran-Nya dalam perumpamaan, bahkan Ia mewujudkannya di dalam pribadiNya. Ia bukan hanya mengajarkan dan memberitakan tentang Kerajaan Allah, tetapi juga isi dari pesan atau proklamasi tersebut. ${ }^{11}$

Michael J. Anthony mengemukakan bahwa Yesus sebagai Guru Agung memiliki prinsip pengajaran melakoni apa yang diajarkan-Nya. ${ }^{12}$ Anthony mengatakan "Yesus mewujudkan pengajaran-Nya di dalam kehidupan dan pelayanan-Nya dengan setia". Hal ini menunjukkan bahwa Yesus sebagai sang guru agung, yang tidak hanya mengajarkan dengan kata-kata, melainkan juga dengan mewujudkan-Nya dalam kehidupan-Nya. Hal inilah yang seharusnya menjadi karakter dasar dalam pendidikan bagi mahasiswa/i di Indonesia. Inilah yang menjadi sumber pemikiran dan moral bagi orang yang mengaku bahwa ia adalah seorang Kristen yang menjadi pengikut Yesus. Pertanyaannya adalah bagaimanakan pendidikan karakter dalam kotbah di bukit yang dibatasi dalam "ucapan bahagia" menurut Injil Matius 5:6-12?

\section{Matius 5:6}

Nats Matius 5:6 ini berbunyi: "Berbahagialah orang yang lapar dan haus akan kebenaran, karena mereka akan dipuaskan." Newman dan Stine berpandangan bahwa haus dan lapar merupakan kata kiasan, yang menunjukkan keinginan orang untuk mencari atau rindu akan

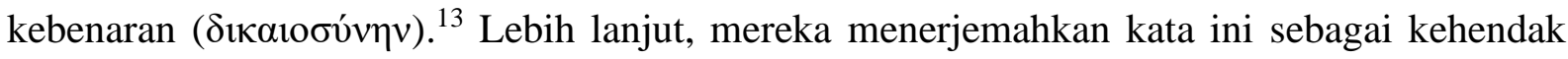
Allah. Pandangan berbeda datang dari Hagner, yang menekankan pengertian lapar dan haus secara literal, yaitu dalam konteks orang-orang yang mengalami penindasan. Mereka lapar dan haus akan keadilan sosial, di mana ini diasosiakan dengan pengharapan apokalipsis dari

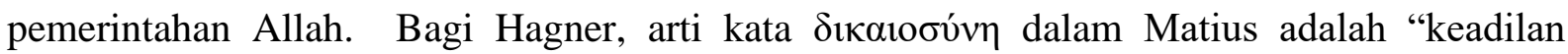
sosial" daripada "kebenaran personal". Mereka yang mengharapkan keadilan sosial Allah dalam pengharapan eskatologis akan menerima berkat-Nya (2Pet. 3:13).

Ucapan bahagia ini merupakan refleksi dari Mazmur 107:9, di mana orang yang haus dan lapar akan kebenaran akan dipuaskan oleh Allah. Kata haus dalam Mazmur 107:9 sama dalam Matius $\chi 0 \rho \tau \alpha \sigma \theta \eta ́ \sigma o v \tau \alpha \iota$ (Mat. 5:6). Kata ini merupakan pengharapan Mesianis dalam Lukas 1:53 menurut Hagner. Mereka adalah orang-orang yang akan dilepaskan daripada masalah (Mzm. 107:2; sama seperti haus akan keselamatan Mzm. 42:1-3; 63:1). France kurang setuju dengan pandangan Hagner yang "menekankan keadilan sosial dari arti kebenaran."14 Baginya, arti kebenaran dalam Matius sangat menekankan tindakan atau perbuatan yang benar, sehingga bersifat individu atau psikologis (Mat. 3:15; 5:20). Yohanes 4:32 menyatakan

\footnotetext{
${ }^{10}$ Joachim Jeremias, Rediscovering the Parables: A Landmark Work in New Testament Interpertation (New York: New Scriber's Sons, 1966), 179.

${ }^{11}$ Ibid, 180.

${ }^{12}$ (Ed) Michael Anthony "Filsafat Pendidikan: Fondasi Pendidikan Abad 21, Terj. Grace Mulyana Lestari dkk (Malang: Gandum Mas, 2017), 198.

${ }^{13}$ Newman dan Stine, Pedoman Penafsiran Alkitab: Injil Matius, 101.

${ }^{14}$ France, The New International Commentary on the New Testament, 167.
} 
bahwa makanan Yesus adalah dengan melakukan kehendak Bapa. Makanan di sini bukanlah makanan fisik, melainkan makanan yang datang dari Allah. ${ }^{15}$

Newman dan Stine, France, serta Osborne memiliki pandangan yang sama mengenai kebenaran yaitu "haus dan rindu akan melakukan kehendak Allah. Mereka harus memiliki perbuatan atau tindakan yang benar dengan taat kepada Allah." ${ }^{16}$ Namun, Keener dan Hagner bersama-sama mengatakan bahwa "konteks kebenaran yang diungkapkan oleh Yesus dalam Kotbah di Bukit adalah dalam Yesaya 25:6; 41:17; 55:2, di mana Allah menyelamatkan mereka dari pembuangan dalam aspek sejarah keselamatan (Ul. 6:11; 8:7-10)." "17 Akan tetapi bagi Keener, hal yang terpenting adalah "objek kerinduan mereka adalah Allah (Mzm. 42:1; 63:1) dan perintah -Nya dalam kebenaran (Mzm. 119:40, 47, 70, 92, 97, 103; Yer. 15:16)."18

Nolland mengatakan bahwa "haus dan lapar akan kebenaran dinyatakan oleh Yesus setelah miskin, berduka, dan rendah hati. Artinya ini adalah kebutuhan manusia yang paling mendasar."19 Kebutuhan manusia ini harus dipenuhi dalam kehidupannya. Baginya, ini bukanlah kebutuhan moral atau orang yang haus lapar atau berhasrat untuk bertindak dalam usaha pribadi dalam bentuk kesalehan. Arti kebenaran di sini adalah: keadilan sosial pada masa itu; pemulihan nama baik dari umat Allah; keadilan sosial yang akan dicapai pada masa eskatologis. ${ }^{20}$ Haus dan lapar akan kebenaran Nolland sama dengan Keener dan Hagner, yaitu keadilan sosial dan pemulihan nama baik dari umat Allah. Konteks inilah yang menjadi permasalahan dalam situasi sosial dalam Matius 5; mereka menunggu Allah bertindak untuk melepaskan mereka dari penderitaan yang mereka alami. Ini merupakan pengharapan umat Allah pada masa itu. Inilah yang disebut sebagai kebenaran tersebut.

Kata $\chi 0 \rho \tau \alpha \sigma \theta \eta ́ \sigma o v \tau \alpha \iota$ (Mat 5:6 yang berbentuk future passive) terutama digunakan untuk memuaskan orang yang lapar. Karena itu, "kata ini digunakan secara natural terhadap haus dan lapar. Pemuasan janji ini secara tepat kepada yang haus dan lapar akan kebenaran." 21 Maka, apa yang dikatakan oleh Newman, Stine, France dan Osborne adalah benar, karena lapar dan haus akan kebenaran merupakan kehendak dari Allah. Kehendak Allah tersebut bukan hanya sebatas pietis seperti yang diungkapkan oleh Newman, Stine, France dan Osborne, namun wujudnya adalah seperti yang diungkapkan oleh Nolland, Keener dan Hagner bahwa lapar dan haus akan kebenaran merupakan kerinduan akan keadilan sosial pada masanya. Hal ini sesuai dengan situasi dan kondisi dalam Injil Matius 5:6-8, di mana situasi politik dan agama yang tidak stabil, di bawah jajahan Romawi. Demikian juga dengan adanya ketegangan antara Kristen mula-mula dengan Yudasime.

\section{Matius 5:7}

Nats Matius 5:7 berbunyi: "Berbahagialah orang yang murah hatinya, karena mereka akan beroleh kemurahan." Rabi Yahudi mengerti bahwa Allah juga akan memuaskan kebutuhan umat-Nya di dalam Kerajaan Allah dimasa yang akan datang (Yes. 25:6; 41:17-18; 55:2),

\footnotetext{
${ }^{15}$ Ibid, 168.

${ }^{16}$ Osborne, Exegetical Commentary on the New Testament, 167.

${ }^{17}$ Keener, The IVP Bible Background Commentary New Testament, 57.

${ }^{18}$ Ibid.

${ }^{19}$ Nolland, The New International Greek Testament Commentary, 202.

${ }^{20}$ Ibid, 203

${ }^{21}$ Ibid.
} 
sama seperti ketika mereka dibebaskan oleh Allah dari Mesir (Ul. 6:11; 8:7-10). Akan tetapi bagi Keener, hal yang terpenting adalah Allah sebagai kehausan dan kelaparan dari manusia (Mzm. 42:1; 63:1) dan juga arahan atau perintah Allah dalam kebenaran-Nya (Mzm. 119:40, 47, 70, 92, 103; Yer. 15:16). ${ }^{22}$

Bagi Newman dan Stine, ini bertentangan kaum Farisi yang mengatakan "Berbahagialah orang yang benar, karena Allah yang bermurah hati pada mereka." Ayat ini sering disalahartikan, bahwa jika seseorang bermurah hati pada sesama, maka orang lain juga akan bermurah hati kepadanya. ${ }^{23}$ Bagi Newman dan Stine, maksud dari kata ini adalah, bahwa Allah sendiri yang akan bermurah hati kepada kita. Arti kata murah hati adalah suatu sifat yang mencakup yaitu, pengasih atau penyayang, suka menolong, baik hati dan mudah mengampuni. Orang yang murah hati adalah orang yang mengasihi orang lain atau yang menunjukkan belaskasihan kepada orang lain. ${ }^{24}$

Osborne berpandangan bahwa ucapan bahagia Yesus dalam Kotbah di Bukit yaitu miskin dalam roh, orang yang berdukacita, lemah lembut, haus dan lapar akan kebenaran pemikiran atau sikapnya merupakan berpusat kepada Allah. Kemudian ucapan bahagia yang lainnya berpusatkan kepada aksi atau tindakan dari manusia atau murid yang diajar oleh Yesus. ${ }^{25}$ Inilah disebut sebagai hidup benar sebagai suatu tindakan atau aksi yang keluar dari dalam hati yang berpusatkan kepada Allah. Bentuknya adalah dengan menunjukkan kemurahan hati kepada sesama manusia yang membutuhkan seperti yang Yesus ungkapkan dalam ucapan bahagia. Ini adalah tuntutan Allah kepada umat-Nya seperti yang terdapat di dalam "Doa Bapa Kami” (Mat. 6:12, 14-15, bersamaan dengan tuntutan memberikan pengampunan kepada orang lain). ${ }^{26}$

Morris memiliki pandangan yang sedikit berbeda dengan Osborne bahwa ucapan bahagia pertama dengan satu dan lainnya cara menyatakan kebergantungan kepada Allah. Sementara bagi Osborne adalah "sebagai suatu kerangka pikir atau sikap hati kepada Allah. Ketiga ucapan bahagia selanjutnya adalah merupakan implikasi dari dari kebergantungan terhadap Allah. ${ }^{27}$ Orang yang bermurah hati kepada orang lain bagi Morris adalah respons kasih Allah dan sedang hidup dalam anugerah-Nya. Secara eskatologis mereka akan menerima kemurahan dari Allah menurut Morris.

Heer juga mengatakan yang sama bahwa Yesus merangsang umat-Nya untuk berbuat baik kepada sesama manusia. Berbuat baik kepada sesama merupakan hal penting yang diajarkan oleh Yesus kepada murid-murid-Nya. Kata murah hati sama dengan perbuatan kasih terhadap sesama manusia menurut Heer. ${ }^{28}$ Yesus mengutip Mazmur 37:11, "Orang-orang yang rendah hati akan mewarisi negeri." Yesus juga mengutip Mazmur 37:21, "Orang benar adalah

\footnotetext{
${ }^{22}$ Keener, The IVP Bible Background Commentary New Testament, 57.

${ }^{23}$ Newman dan Stine, Pedoman Penafsiran Alkitab: Injil Matius, 102.

${ }^{24}$ Ibid.

${ }^{25}$ Osborne, Exegetical Commentary on the New Testament, 168.

${ }^{26}$ Ibid.

${ }^{27}$ Morris, Injil Matius, 106.

${ }^{28}$ J.J. de Heer, Tafsiran Alkitab: Injil Matius Pasal 1-22, 71.
} 
pengasih dan pemurah." Orang yang memiliki kemurahan akan mewarisi kemurahan dari Allah pada waktu akhir jaman. ${ }^{29}$

France berpandangan bahwa prinsip timbal balik berlaku dalam Injil Matius. Hal ini "berhubungan dengan kemurahan dan pengampunan (lihat dalam Mat. 6:14-15 dalam dalam tafsirannya dalam 18:21-35)." 30 Bagi France, "the golde rule" dalam Matius 7:12, "Segala sesuatu yang kamu kehendaki supaya orang perbuat kepadamu, perbuatlah demikian juga kepada mereka. Itulah isi seluruh hukum Taurat dan kitab para nabi", merupakan hati atau jantung dari etika Yesus. ${ }^{31}$ Kata "kemurahan" lebih luas dari pada pengampuan menurut France, di mana ini merupakan sikap yang baik hati yang rela melihat dari sudut pandang lain atau dari sisi yang lain, dan tidak langsung menyalahkan atau menyerang orang lain (ini merupakan keutamaan kasih dalam 1 Kor. 13:4-7). ${ }^{32}$ Hal ini bukanlah respon terhadap orang yang murah hati, melainkan bagaimana hidup dengan standar Allah. ${ }^{33}$ Ini bertentangan dengan Heer maupun Morris yang menyatakan ini merupakan respon atas anugerah Allah.

Hagner mengatakan bahwa kelima ucapan bahagia menekankan hal yang baru, di mana keempat pertama merupakan kerangka pikir atau sikap dalam hati seperti yang diungkapkan oleh Osborne. ${ }^{34}$ Orang yang berbahagia adalah orang yang bertindak atau yang melakukan kemurahan hati kepada orang lain. Penekanannya terdapat dalam Pengkotbah 17:5c, yang mengatakan bahwa diberkatilah orang yang memiliki kemurahan hati terhadap orang miskin. Menunjukkan belas kasihan merupakan unsur kunci atau penting dari ajaran para rabi. Kemurahan merupakan bagian terpenting dalam etika Matius 9:13; 12:7; 23:23. Apa yang tidak diperoleh oleh orang miskin dan tertindas dari orang kaya dan yang berkuasa seharusnya tidak mereka lakukan kepada orang lain. ${ }^{35}$ Orang yang melakukan kekerasan atau penindasan terhadap orang dan tidak menunjukkan belas kasihan akan dihakimi pada akhir jaman.

Kemurahan hati merupakan standar dari panggilan orang Yahudi di hadapan Allah. "Ini merupakan bukti ketaatan atau ketundukan terhadap perintah Allah. Perjanjian Lama mengidentifikasikan bahwa Allah adalah pemurah. ${ }^{36}$ Panggilan untuk murah hati merupakan tradisi hikmat Israel dan ini merupakan salah satu beban dari para nabi. ${ }^{37}$ Orang-orang yang mengalami penindasan akan sangat sukar untuk menyatakan kemurahan kepada orang lain. Di hati mereka, ada balas dendam terhadap orang yang telah menindasnya. Oleh sebab itu, kemurahan hati merupakan suatu tindakan atau aksi yang ditunjukkan dalam kehidupan. ${ }^{38}$

\section{Matius 5:8}

Nats ini berbunyi: "Berbahagialah orang yang suci hatinya, karena mereka akan melihat Allah." Arti kata hati dalam bahasa Yunani bagi Newman dan Stine adalah jantung, bukan hanya mengenai perasaan atau emosi manusia, tetapi juga mencerminkan keadaan di dalam

\footnotetext{
${ }^{29}$ Ibid.

${ }^{30}$ France, The New International Commentary on the New Testament, 168.

${ }^{31}$ Ibid.

${ }^{32}$ Ibid.

${ }^{33}$ Ibid.

${ }^{34}$ Hagner, Word Biblical Commentary Matthew 1-13, 93.

${ }^{35}$ Ibid.

${ }^{36}$ Nolland, The New International Greek Testament Commentary, 203.

${ }^{37}$ Ibid, 204.

${ }^{38}$ Ibid.
} 
diri atau nurani orang itu yang telah membentuk hidupnya. ${ }^{39}$ Dalam budaya Ibrani, hati merupakan pusat kepribadian seseorang dan digunakan sebagai lambang dari pikiran, perasaan, dan jiwa seseorang. Lambang hati dapat digunakan untuk menunjukkan sikap sesorang terhadap lawan jenisnya (Mat. 5:28); dan terhadap uang (Mat. 6:20-21).

Bagi Keener, konteks hati suci berasal dari Mazmur 73:1, adalah orang-orang Israel yang hatinya bersih karena mereka mengenal Allah, di mana Allah sendiri yang akan menolong mereka dan memberikan berkat (Mzm. 73:2-28). ${ }^{40}$ Kebenaran Allah akan terlihat pada hari penghakiman (Yes. 30:20), seperti yang terjadi pada saat bangsa Israel keluar dari Mesir (Kel. 24:10-11). Nolland melihat bahwa "ucapan bahagia ini bukanlah mengenai kebutuhan khusus seseorang atau manusia. Orang yang memiliki hati bersih berlawanan dengan konteks pada masa itu dengan orang penindas." 41 Dalam Mazmur 24:3-4, hanya orang-orang yang memiliki hati yang bersihlah yang dapat mendaki gunung Allah (masuk ke dalam Bait Allah, dan yang mencari wajah-Nya (ay. 6). Kemurnian hati yaitu integritas yang berlawanan dengan penindas yang licik. Orang yang licik memiliki hati maksud tersembunyi di dalam setiap tindakannya (kecednerungan motivasinya adalah buruk). Hati merupakan salah satu esensi atau hakikat dari seseorang, yang akan menentukan perasaan, pikiran dan tindakan atau perbuatan." ${ }^{22}$

Hagner berpandangan bahwa "hati murni atau bersih dihubungkan dengan orang merasa bersalah dan meminta ampun (Mzm. 51:10; 73:1)."43 Merekalah yang dapat datang ke hadapan Allah. Definisi hati Hagner sama halnya dengan Nolland, yaitu hakikat dalam diri seseorang yang terdiri dari pemikiran dan motivasi seseorang. Oleh sebab itu, nilai-nilai Kotbah di Bukit di internalisasikan dalam diri seseorang. Hal in menuntut tindakan yang benar, namun disertai dengan integritas dalam tindakan tersebut. Contohnya adalah kesesuaian atau kesinambungan antara batin seseorang dengan tindakannya atau aksinya. Hati nurani yang bersih dan kesadaran yang bersih berhubungan dengan surat pastoral atau pengembalaan dalam 1 Timotius 1:5; 3:9; 2 Timotius 1:3; 2:22; 1 Petrus 1:22.

Menurut Hagner bahwa Matius melihat bahwa ada janji eskatologis (hadiah atau pahala) bagi mereka yang memiliki hati nurani yang murni. Ucapan bahagia ini sangat sukar untuk dihubungkan dengan yang lain. Namun, ini mengindikasikan bahwa orang-orang murni hatinya yang mengalami aniya, penindasan dan orang miskin yang menerima berita kabar baik ini akan diterima oleh Allah dan akan masuk ke dalam Kerajaan Allah. Akan tetapi, hal ini tidak bisa menjadi suatu presuposisi bagi Hagner.

Morris mengatakan bahwa "hati merujuk kepada keseluruhan batin, pemikiran, kehendak dan emosi dalam diri manusia. Dalam pengertian psikologi, hati merupakan tempat bagi daya kolektif manusi, fokus kepada kehidupan pribadi bagi unsur rasional, emosional dan panggilan dalam kehidupan manusia, sehingga inilah menjadi pusat moral dan keagamaan manusia." 44 Maka bagi Morris, "ucapan bahagia Yesus dalam Matius bersifat eskatologis

\footnotetext{
${ }^{39}$ Newman dan Stine, Pedoman Penafsiran Alkitab: Injil Matius, 102.

${ }^{40}$ Keener, The IVP Bible Background Commentary New Testament, 58.

${ }^{41}$ Nolland, The New International Greek Testament Commentary, 204.

${ }^{42}$ Ibid, 205.

${ }^{43}$ Hagner, Word Biblical Commentary Matthew 1-13, 94.

${ }^{44}$ Morris, Injil Matius, 106.
} 
yaitu menunjuk pada visi yang besar yang dialami oleh manusia dalam kehidupan di dunia, di mana ini akan mencapai puncaknya di masa yang akan datang." ${ }^{25}$

\section{Matius 5:9}

Matius 5:9 berbunyi: "Berbahagialah orang yang membawa damai, karena mereka akan disebut sebagai anak-anak Allah." Orang pembawa damai menurut Newman dan Stine adalah orang yang membawa damai bagi sesama manusia (Ibr. 12:14; Ef. 2:15; Yak. 3:18). ${ }^{46}$ Ini berasal dari sastra Yahudi. Kata ini dapat dipakai sebagai membuat kawan satu dengan yang lain, dan dapat juga diterjemahkan sebagai menolong orang lain agar dapat hidup damai. Kata ini juga dapat diterjemahkan sebagai mencegah permusuhan dengan orang lain, agar terjadi kedamaian.

Osborne mengungkapkan bahwa Yesus mengajarkan agar terjadi rekonsiliasi antara Allah dan manusia, dan manusia dengan sesamanya agar tidak terjadi permusuhan. ${ }^{47}$ Ajaran Yesus ini yaitu sebagai pembawa damai, bertentangan dengan murid Yesus yaitu Simon Zelot (Mat. 10:4), karena ia ingin Israel merdeka dari Roma dengan perang. Hal ini senada dengan Hagner, bahwa ini merupakan revolusi Yahudi terhadap penjajahan Roma. Yesus berbeda dengan pandangan tersebut, yaitu dengan cara damai dan bukan perang. Perdamaian merupakan cara yang dilakukan oleh anak-anak Allah (Rm. 9:26). ${ }^{48}$ Perdamaian menurut Morris adalah dengan membalas kejahatan dengan kebaikan. ${ }^{49}$

Tindakan dari pembawa damai adalah akibat tidak adanya atau absennya kedamaian bagi Nolland.$^{50}$ Oleh sebab itu, konteks sosial politik harus diperhatikan dalam bagian ini. Usaha perdamaian diakibatkan oleh adanya permusuhan atau perselihan maupun konflik yang sedang terjadi. Usaha perdamaian bukanlah karena adanya golongan atau partai atau orang ketiga, melainkan inisiatif seseorang atau individu yang melakukannya. Mazmur 34:14, merupakan merupakan panggilan untuk mencari perdamaian dan mengejarnya dalam kehidupan umat Allah. Bagi Nolland, orang yang menerima ucapan bahagia Yesus akibatnya adalah menerima pengampunan, melihat Allah dan menjadi anak-anak Allah (status hidup dalam perjanjian dengan Allah). ${ }^{51}$

Orang yang mencari perdamaian merupakan karakteristik atau ciri dari umat Allah menurut France (Mzm 34:14). ${ }^{52}$ Ucapan bahagia ini melampaui usaha untuk mencari perdamaian, mungkin juga dengan mengusahakan rekonsiliasi dengan musuhnya, tetapi juga membawa bersama orang-orang yang saling bermusuhan untuk duduk bersama, sehingga terjadilah perdamaian. Usaha perdamaian dituntut dengan harga yang sangat besar yaitu dengan ajaran Yesus dalam Matius 5:39-42, mengenai hukum lex talionis. ${ }^{53}$ Dalam kondisi perang, ketidakadilan, penganiyaan merupakan hal yang biasa bagi dunia, maka yang dituntut

\footnotetext{
${ }^{45}$ Ibid, 107.

${ }^{46}$ Newman dan Stine, Pedoman Penafsiran Alkitab: Injil Matius, 103.

${ }^{47}$ Osborne, Exegetical Commentary on the New Testament, 169.

${ }^{48}$ Hagner, Word Biblical Commentary Matthew 1-13, 94.

${ }^{49}$ Morris, Injil Matius, 107.

${ }^{50}$ Nolland, The New International Greek Testament Commentary, 204.

${ }^{51}$ Ibid, 205.

${ }^{52}$ France, The New International Commentary on the New Testament, 169.

${ }^{53}$ Ibid.
} 
oleh Yesus dalam kondisi demikian adalah mencari damai. Efeknya bagi France adalah menjadi anak-anak Allah (Mat. 5:44-45). Anak-anak merupakan idiom dalam bahasa Semit, yaitu berbagi karakter atau status. Contohnya Matius 9:12 ada istilah "anak-anak Kerajaan Allah", atau dalam Matius 13:38 terdapat istilah "anak-anak kejahatan."54 Jadi, anak-anak Allah di sini adalah memiliki karakter seperti Allah, karena mereka telah ada dalam perjanjian seperti yang dinyatakan oleh Osborne.

\section{Matius 5:10-12}

Matius 5:10-12 berbunyi: "Berbahagialah orang yang dianiya oleh sebab kebenaran, karena merekalah yang empunya Kerajaan Sorga. Berbahagialah kamu, jika karena Aku kamu dicela dan dianiaya dan kepadamu difitnahkan segala yang jahat. Bersukacita dan bergembiralah, karena upahmu besar di sorga, sebab demikian juga telah dianiaya nabi-nabi yang sebelum kamu." Menurut Hagner, paradoks ucapan bahagia mencapai titik klimaks dalam Matius 5:10-12 yaitu ucapan bahagia yang ke sembilan, yaitu orang teraniaya karena kebenaran. ${ }^{55}$

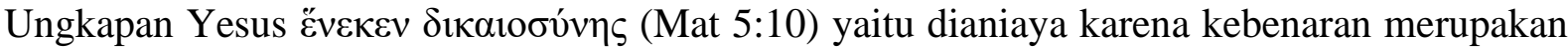
ciri dari orang yang hidup dalam Kerajaan Allah. Mereka mengalami penderitaan karena setia dan taat terhadap panggilan Allah dalam kehidupan mereka. Bagi Hagner, teridentifikasi dengan Yesus Kristus dan dalam Kerajaan Allah adalah jalan kebenaran (Mat. 21:23). Istilah

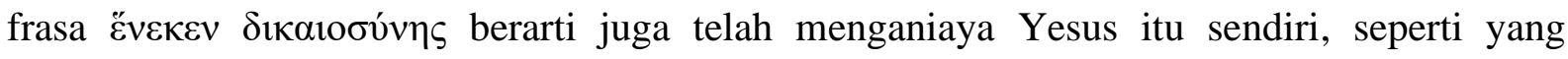
terdapat dalam Matius 10:22.

Tema penganiyaan dalam Kitab Matius merupakan sesuatu yang cukup penting bagi Hagner, karena ini merupakan refleksi dari kehidupan jemaat ketika Injil ini ditulis. ${ }^{56}$ Jemaat mula-mula dianiaya oleh saudara mereka sendiri, yaitu orang Yahudi. Oleh sebab itu, "mereka ingin mengetahui mengapa mereka mengalami penderitaan aniaya tersebut dan bagaimana mereka dapat menghadapinya. Hal yang sama dalam 1 Petrus 4:12-14 (3:14) digunakan oleh Matius 5:44, agar pembaca Injil Matius tetap berdoa dalam penganiayaan. ${ }^{57}$ Orang yang telah menjadi pengikut Yesus akan mengalami penganiayaan menurut France, karena ini adalah harga yang harus dibayar (Mat. 10:16-39; 22:6; 23:29-36; 24:9-13). ${ }^{58}$ Ia mengatakan bahwa orang yang mengenal kebenaran akan dianiaya dalam Yesaya 51:7. Morris menambahkan bahwa orang yang menderita aniaya juga karena imannya kepada Allah dan melakukan kehendak-Nya. ${ }^{59}$

Nolland mengatakan bahwa "ucapan bahagia Yesus seperti belas kasihan atau kemurahan, hati yang suci dan menjadi agen perdamaian adalah tanda-tanda kebenaran yang akan mengalami penderitaan karena telah memerjuangkannya. ${ }^{60}$ Penderitaan karena aniaya sebagai tanda dari kompromi dan kemurtadan, di mana ini merupakan suatu tanda dari kesetiaan dan ketaatan kepada Allah. ${ }^{61}$

\footnotetext{
${ }^{54}$ Ibid.

${ }^{55}$ Hagner, Word Biblical Commentary Matthew 1-13, 94.

${ }^{56}$ Ibid.

${ }^{57}$ Ibid, 95 .

${ }^{58}$ France, The New International Commentary on the New Testament, 170.

${ }^{59}$ Morris, Injil Matius, 108.

${ }^{60}$ Nolland, The New International Greek Testament Commentary, 206.

${ }^{61}$ Ibid, 207.
} 


\section{Pendidikan Karakter Berdasarkan Matius 5:6-12}

Kerangka pemikiran atau pandangan dunia tentang pendidikan karakter menurut Yesus didasarkan pada perubahan batin dalam diri seseorang. Ini adalah motif atau dasar dari setiap manusia untuk melakukan segala sesuatu atau tindakan serta karakter. Ini dimulai dengan perubahan mental atau batin seseorang atau apa yang disebut revolusi batin manusia. Hal ini sangat penting karena merupakan perubahan mendasar dalam diri manusia dan membuatnya bermartabat dan manusiawi. Gill dalam Nuhamara, "terutama karakter moral. Mungkin, itu praktik yang baik, jika kita membayangkan apa yang orang akan katakan pada saat pemakaman kita. Bukan gelar, harta yang akan mereka katakan tetapi karakter kita, bahwa kita sebagai orang dermawan yang membantu atau orang akan mengatakan kita pelit pada orang." ${ }^{62}$ Dalam kaitannya dengan pendidikan karakter, pendidikan karakter adalah suatu upaya sadar dan sistematis dan berkesinambungan untuk membangun karakter (baik) dalam siswa (anak, remaja, pemuda dan orang dewasa) sehingga pelajar tahu apa yang baik (dimensi kognitif), dimensi afeksi (affective dimension), dan melakukan yang baik dalam hidup (aspek psikomotor dan perilaku). ${ }^{63}$

Revolusi mental adalah dalam semua aspek dari seseorang, tubuh atau daging, pikiran, perasaan, kehendak, emosi, hati. Semua aspek manusia ini tidak dapat dipisahkan satu sama lain sehingga mereka tidak jatuh ke dalam dualisme. Di sisi lain, revolusi yang dirujuk dalam artikel ini bukanlah sebuah revolusi sosial politik yang berdarah atau dengan banyak korban manusia yang dilakukan melalui peperangan. Oleh karena itu, menurut Yesus dalam ucapan bahagia adalah orang yang miskin dalam Roh atau miskin dalam Roh; berkabung atas dosa dan ketidaksalehan atau ketidakadilan sosial, sehingga mereka mengharapkan bantuan dari Allah; yang lemah lembut yang tidak sombong dan tidak menyalahgunakan kekuasaannya; kelaparan dan kehausan terhadap kebenaran; dan bersih atau murni hatinya. Revolusi batin ini harus dilanjutkan oleh pendidik Kristen. Pendidik Kristen tidak hanya mengajarkan poin iman Kristen ${ }^{64}$, melainkan juga memberikan contoh sebagai bagian dari mental revolusi mental.

Revolusi praksis adalah deskripsi revolusi batin dalam diri seseorang. Yesus mengatakan bahwa pohon itu akan terlihat dari buah atau buah pohon jatuh tidak jauh dari pohonnya. Motivasi dalam seseorang atau isi dari pikiran seseorang atau jiwa menjadi karakter yang dapat dilihat oleh banyak orang. Ini adalah terjemahan dari revolusi mental manusia. Bentuknya yang konkret adalah murah hati, rekonsiliator atau pembawa damai, dan bersedia untuk menderita dan dianiaya demi kebenaran dan demi Yesus Kristus sendiri. Dengan demikian, pendidikan karakter sesuai dengan ajaran Yesus dalam "ucapan bahagia" dalam khotbah di bukit adalah dasar teologi dari pendidikan karakter bagi siswa Kristen. Pendidikan karakter adalah embrio perubahan sosial dalam masyarakat. Ajaran Yesus mencakup dan menyentuh semua aspek atau aspek kemanusiaan itu sendiri, yaitu revolusi batin dan Praxis manusia.

\footnotetext{
${ }^{62}$ Daniel Nuhamara, "Pengutamaan Dimensi Karakter Dalam Pendidikan Agama Kristen,” Jurnal Jaffray 16, no. 1 (2018): 93, https://doi.org/10.25278/jj71.v16i1.278.

${ }^{63}$ Nuhamara.

${ }^{64}$ Binsen Samuel Sidjabat, "Kerangka Kurikulum Pendidikan Agama Kristen Berbasis Karakter Di Perguruan Tinggi Character-Based Christian Religious Education Curriculum Framework in Higher Education," Jurnal Jaffray 17, no. 1 (2019): 73-90, https://doi.org/10.25278/jj.v17i1.314.
} 


\section{Kesimpulan}

Ucapan bahagia (Mat. 5:6-8) dapat digunakan sebagai landasan pendidikan karakter bagi siswa dan juga orang lain. Dasar teologi adalah revolusi batin (jiwa) dan praksis dalam diri manusia, yaitu siswa Kristen. Kesesuaian antara kata dan tindakan manusia atau tindakan itu sendiri. Ini adalah seluruh aspek kehidupan manusia tanpa menjadi dualistik. Pertemuan dengan Kristus, disertai dengan pendidikan adalah metode yang unik dan unik dalam pendidikan Kristen yang berbeda dari pendekatan pendidikan umum lainnya. Referensi ini menjadi pandangan atau pandangan dunia atau kerangka pikiran dari pendidikan karakter Kristen di dunia pendidikan dan juga orang lain. Ini akan membuat siswa menjadi orang yang bergantung pada Allah, humanis, rendah hati, integritas, empati sosial, memaafkan, membantu atau peduli dengan sesama manusia, seorang rekonsiliator. Jadi, dampaknya adalah perubahan sosial dalam masya-rakat, baik di gereja, sekolah dan negara.

\section{Referensi}

Anthony, Michael, ed. Filsafat Pendidikan: Fondasi Pendidikan Abad 21. Malang: Gandum Mas, 2017.

Boiliu, Noh Ibrahim. "Misi Pendidikan Agama Kristen dan Problem Moralitas Anak." Regula Fidei 1, no. 1 (2016): 115-40. https://doi.org/DOI: 10.33541.

Boiliu, Noh Ibrahim, and Christina Metallica Samosir. "Manusia Sebagai Makhluk Moral dalam Perspektif Teologia Pendidikan Johann Heinrich Pestalozzi.” Jurnal Dinamika Pendidikan 12, no. 3 (2019): 187-97.

France, R. T. The New International Commentary on the New Testament: The Gosple of Matthew. Edited by Ne B Stonehouse. Grand Rapids: Eerdmans Publishing Company, 2007.

Gertz, Jan C. Purwa Pustaka. Jakarta: BPK Gunung Mulia, 2017.

Hagner, Donald. A. Word Biblical Commentary Matthew 1-13. Edited by Bruce M Metzger. Nashville: Thomas Nelson, 2000.

Heer, J. J. de. Tafsiran Alkitab: Injil Matius Pasal 1-22. Jakarta: BPK Gunung Mulia, 2001. Jeremias, Joachim. Rediscovering the Parables: A Landmark Work in New Testament Interpertation. New York: New Scriber's Sons, 1966.

Keener, Craig S. The IVP Bible Background Commentary New Testamen. Downers Grove: IVP Academic, 1993.

Koesoema, Albertus Doni. Mencari Format Pendidikan Karakter Dalam Konteks Keindonesiaan. Yogyakarta: Kanisius, 2010.

Kung, Hans. On Being A Christian. New York: Doubel \& Company, 1974.

Martinez, F. Garcis, ed. STUDIES IN DEUTERONOMY: In Honour OfC.J. Labuschagne on the Occasion Ofhis.65th Birthday. VIII. Leiden.New Yor. Koln: E.J. Brill, 1994.

Morris, Leon. Injil Matius. Surabaya: Momentum, 2016.

Newman, Barclay M, and Philip C Stine. Pedoman Penafsiran Alkitab: Injil Matius. Jakarta: LAI, 2008.

Nolland, Jhon. The New International Greek Testament Commentary: The Gosple of Matthew. Edited by Howard I Marshall. Grand Rapids: Eerdmans Publishing, 2005.

Nuhamara, Daniel. "Pengutamaan Dimensi Karakter Dalam Pendidikan Agama Kristen." Jurnal Jaffray 16, no. 1 (2018): 93. https://doi.org/10.25278/jj71.v16i1.278.

Osborne, Grant R. Exegetical Commentary on the New Testament. Edited by Clinton E Arnold. Grand Rapids: Zondervan Publishers, 2010. 
Pike, Mark A. "The Value of Christian-Ethos Schooling for Secular Students." Journal of Research on Christian Education 20, no. 2 (2011): 138-54. https://doi.org/10.1080/10656219.2011.590728.

Sidjabat, Binsen Samuel. "Kerangka Kurikulum Pendidikan Agama Kristen Berbasis Karakter Di Perguruan Tinggi.” Jurnal Jaffray 17, no. 1 (2019): 73-90. https://doi.org/10.25278/jj.v17i1.314.

Sihombing, Aeron Frior. "Pendidikan Kristen Yang Mencerahkan".” Jurnal Te Deum: Jurnal Teologi Dan Pengembangan Pelayanan 5, no. 2 (2016): 151.

Silalahi, Haposan. "Sebuah Metode Hermeneutik Dalam Menemukan Makna Yang Tersembunyi Dalam Teks-Teks Alkitab.” Jurnal Te Deum-Jurnal Teologi Dan Pengembangan Pelayanan 8, no. 1 (2018): 47-49.

Wilhelm, Gretchen M., and Michael W. Firmin. "Character Education: Christian Perspectives." Journal of Research on Christian Education 17, no. 2 (2008): 182-98. https://doi.org/10.1080/10656210802433384. 